\title{
Introduction: Reflections on higher education and the public good
}

\author{
Brenda Leibowitz
}

\section{Why higher education for the public good?}

here is always a potential contribution that higher education can make to the public good. In the twenty-first century specific concerns that require our attention are sustainability and global warming, human mobility and migration and peculiarly contemporary diseases such as AIDS. These can be seen as contemporary manifestations of protean and oft-recurring social and natural ills such as war and conflict, food insecurity and religious and ideological rivalries - phenomena to which higher education applies its collective mind and know-how. The greater the technological advances we make, for example in health provision and communications technology, the greater the frustration that we cannot do more to make the world a better place. Despite the enormous potential of higher education as an institution to contribute to the public good, it does not deliver on this potential, as Saleem Badat, the vice chancellor of Rhodes University, observes:

Higher education holds the promise of contributing to social justice, development and democratic citizenship. Yet, this promise often remains unrealised and universities, instead, frequently continue to be a powerful mechanism of social exclusion and injustice. (2010:6)

Mala Singh, Martin Hall and Crain Soudien elaborate on the reasons why higher education is constrained from delivering on this potential in section one of this book. The rest of the contributors focus on ways individuals and groups have grappled with this challenge. 


\section{Why perspectives from the South?}

South Africa is in the South geographically as well as politically. So much that is written about higher education in general, and higher education for the public good in particular, stems from the developed North. This provides a distorted vision of what higher education for the public good might entail. Approaches to knowledge are embedded in place and culture - and the periphery has something valuable to contribute to knowledge of the metropole (Connell, 2007). Contributions from the South have a particular value conditions are different and the particular experience of struggle against injustice and for equality and human flourishing takes on forms which may differ in terms of both content and intensity, from forms in the developed world. By way of example, in her account of teaching postgraduate teachers in Khayelitsha, a township in the Cape Metropolitan area of South Africa, McNiff, a non-South African visitor, described how the experience re-educated her in joyful and painful ways about the quality and purpose of her teaching. Subreenduth, an ex-South African living in Ohio, argues that her experience of living in South Africa makes her approach to issues of difference more critical and nuanced. To contextualise the contents of this volume, some comments about the situation South African higher education finds itself in due to its apartheid legacy and its present attempts to deal with this are required.

Paradoxically, a positive legacy of the struggle against apartheid, characterised by colonial foreign domination and, later, local minority racist oppression, is the collective memory of injustice. Operating in the country for over three centuries - from 1652 to 1994 - the oppression was so overwhelming and extensive that today there exists a widely held belief that the majority of its institutions and society need to be transformed. Von Holdt (2012:202) refers to the symbolic struggle between the popular movement and the apartheid regime', which 'laid the basis for the emergence of a new symbolic order centred on the idea of democracy and the transformation of the social structures of racial domination in the economy and society'. This collective belief binds individuals from a variety of political and cultural backgrounds, and helps institutions work towards change and the public good. This belief is held at a very general level, and is not necessarily interpreted in the same way by individuals from varied political persuasions, which is why issues related to equality, such as affirmative action, are highly contested in South Africa.

There are those who would wish to return to the apartheid dispensation but they are firmly in the minority. Whilst the collective aspiration is towards a 
public good, there has been a degree of fragmentation of the collective aspiration. According to Chidester et al, in post-apartheid South Africa 'everything is pulling us apart' (2003:ix). During the apartheid period the enemy was clear and the solutions - at least for those who were politically engaged - were easy to describe, as they were cast in terms of the future and aspirations. Von Holdt (2012:203) refers to 'new hierarchies and distinction, new interests, and new social distances'. Thus whilst there remains a pervasive sense of public purpose, amongst public intellectuals and educators there is a strong degree of contestation and confusion.

A significant feature of South African society which gives higher education its peculiar flavour and makes transformation so urgent is the relative underdevelopment of the economy. While South Africa's economy is the largest in Africa it significantly lags behind developed nations, and this restricts the extent to which it can fund public higher education. Furthermore, funding for public higher education in South Africa is comparatively lower than in countries at a similar stage of economic development (Scott, 2009). Expenditure on higher education in the country is 2.7 per cent, as opposed to 3.3 per cent for the rest of the world (National Advisory Council on Innovation [NACI], 2006). This combination of urgency and potential is summed up in the sub-title of Unesco's Taskforce report on education (2000): Higher education in developing countries: peril and promise. A limitation of the sector, as well as a motivating force for change, is the degree of financial inequality between higher education institutions and between individuals. The measure for South Africa of economic inequality between individuals, known as the Gini-coefficient, is one of the highest in the world (Bosch et al, 2010; Hall, chapter two). The amount of resources a university has, the extent to which it operates within an inclusive and pro-social-justice ethos, and its ability to execute its mission is different for each South African institution. Such variation exists because the South African higher education system is fragmented in terms of funding and institutional autonomy (Council of Higher Education, 2008) - a legacy of the apartheid era perpetuated in the current era. The fragmentation is also perpetuated by the varying leadership, skills base and management cultures at higher education institutions.

A further feature influencing the ability of higher education in South Africa to teach for the public good is the low and skewed participation of the appropriate cohort of 18-24-year-olds. This exists partly because schooling is unable to increase the pool of potential students (Bray et al, 2010; Morrow, 2007) and partly because of the elitist nature of higher education itself. In 2009 public participation in higher education was 17 per cent (Council for Higher Educa- 
tion Website), in comparison to a global participation rate of 26 per cent in 2007 (Altbach et al, 2009). Furthermore, participation rates vary according to various biographical factors, most notably race. In 2009 the participation rate for whites was 57 per cent, whereas for Africans it was 13 per cent (Council for Higher Education website). The participation rate is also skewed according to university type and discipline (Council for Higher Education website), with historically advantaged universities attracting more middle-class, white and even international students than historically disadvantaged universities. The relationship between social inequality and race mirrors the international situation, where participation is skewed in favour of the privileged (Altbach $e t$ $a l, 2009)$. A low or skewed participation implies that too few graduates would be able to contribute to the public good in the future; graduates could arguably contribute in sectors according to preferences influenced by the demographic make-up of the student cohort at any university.

As with other countries in which higher education was founded during the colonial era (Parra-Sandoval et al, 2010), South Africa shares an approach to knowledge which is derivative rather than leading. Badat (2009) writes that though South African higher education has transformed to a degree, there have been limited changes to the decolonisation of knowledge. It consumes western theories rather than helping to generate them (de Souza, 2007:135). This is not only due to the peripheral position of the country, the negative effects of the brain drain (Botman, 2011) and poor infrastructure (OndariOkemwa, 2011) - the country's knowledge dissemination network is also rather weak. Recent pressure for academics to publish has led more of these studies to find their way into international journals, but not as much into locally published or internationally distributed books. Two notable recent exceptions of publications on higher education, and indications that the trend may be reversing, are Bitzer (2009) and Bitzer and Botha (2011). The size of the South African academic book buying public has a negative impact on the ability to write, publish and disseminate original knowledge. Knowledge practices have not been fundamentally overhauled since apartheid ended.

A further feature influencing higher education in South Africa and its ability to administer to the public good is the depth of the social cleavages based on social class, race and, to an extent, language. This impacts on issues of identity and the sense of inclusion and exclusion for students (Cross and Johnson, 2006; Erasmus, 2006) and academics (Vandeyar, 2010; Hemson and Singh, 2010). The increasingly prominent role of social class in the interrelationship between race and class and how they influence perceptions and interactions between students is explored by Pattman (2010), amongst 
others. Such is the extent of this cleavage - and the challenges it poses to harmony and disharmony as well as to student success at universities - that a ministerial task team was initiated with a report produced in 2008 (Ministerial Committee, 2008). Challenges are posed to educators whose positionality and biography influence their teaching and, moreover, their ability to teach for the public good. Jansen (2009) has a metaphor which aptly conveys how deeply educators' and students' subjectivities are influenced by history and their own educational and social biographies. He terms this 'knowledge in the blood'.

From a policy perspective, two positive features of the present era in South Africa are the progressive and pro-social-justice policy discourse (Lange, chapter four) and an accountability and quality assurance discourse which is less prescriptive and imposing than in many other countries such as Australia or the United Kingdom. All policy statements emanating from the South African state pertaining to higher education stress the imperative to transform higher education so that it becomes more equitable in terms of participation and governance, and so that it contributes to the public good and social justice. There is an emphasis on the need for higher education to have an influence beyond the country with regard to social accountability and the potential of higher education (CHE, 2008). What is significant about policy documents in the post-apartheid period is the emphasis on the role of teaching:

The Task Team is convinced that, if it rests on the South African Constitution, the reformulation of academic freedom promises to yield all round and future benefits. This is because the 'greatest contribution the academy makes to empowering a society ... is ... through what and how universities teach'. (CHE, 2008:20)

With regard to the accountability regime, the country's institutions are subject to steering via a quality assurance mechanism, funding mechanisms and planning requirements (CHE, 2008). However the quality assurance mechanism poses less of a constraint than equivalent regimes in the United Kingdom or Australia, possibly because of the lack of capacity of the system and possibly because of the collective memory and resistance to dominance and prescription which was so prevalent during the apartheid era. In addition to the emphasis on the role of teaching in relation to transformation and the public good, the quality assurance regime strongly emphasises institutional transformation via its particular interpretation of the phrase 'fitness of purpose' (CHE, 2008). This is discussed in detail by Lange (chapter four). 
In short, the South African perspective has much to contribute to international debates on the public good for the following reasons: its particular history and the present makeup of its society; the urgency and intensity of the need for social transformation; and its long history and experiences of attempts at teaching for the public good. In his contribution to the Global Poverty Summit in Johannesburg in 2011, Russel Botman argued that with regard to partnerships between the North and South, Africa tends to exist in a relationship of dependency and it is time for Africa to increasingly take on the role of the lead agent (2011). This book is intended to be one small contribution towards this end.

\section{What is 'higher education for the public good'?}

The term 'public good' is very broad and can include a variety of ideologically informed positions. In this volume it is described by Bozalek and Leibowitz (chapter five) as a concern with participatory parity and equality, not the privileged and wealthy administering charity to the marginalised. Bozalek and Leibowitz stress the relevance of reciprocity and relationality, with reference to the ethic of care. They refer to the importance of the flourishing of human beings as a valuable end, instead of seeing human beings as instruments of economic well-being. The emphasis on humans and their flourishing rather than on humans as instruments, associated with the capabilities approach, is discussed in the contributions by Hall and Walker. The public good is often defined in material terms, as if it is visible, countable or weighable. In this volume, however, the public good is associated with how people or groups think and behave. Some important components of pro-public-good thought or behaviour are offered for consideration in the book. These are ethical competences (Boni, MacDonald and Peris), reflexivity (Costandius), criticality (Soudien, Subreenduth), care (Bozalek and Leibowitz), humanity (Waghid) and hopefulness (Waghid, Nicholls and Rohleder).

Higher education is often described as a public good in that it generates technological know-how, knowledge in service of professions and a critical citizenry, in both developed and developing countries (Botman, 2012; Taskforce on Higher Education and Society, 2000; Habermas, 1971). Furthermore, higher education can bring material well-being to graduates (Association of Commonwealth Universities, 2011) and may open opportunities for social and educational mobility for those students whose parents were not in 'graduate level occupations' (Hall, chapter two). This is higher education as a public resource which brings material or intellectual benefits to individuals or society - higher education as a public good. The title of this volume - 'Higher 
Education for the Public Good' - conveys something more intentional and deliberate. It is the idea that we can conduct the three roles of higher education - research, teaching and community interaction - in such a way that we reflect upon who higher education is for, who it can serve, and how.

\section{Implications for higher education institutions}

Higher education for the public good implies that the institution as a whole be predisposed - via its mission, culture and practices both within the institution and in its dealings with the outside world - towards social justice, inclusion and care for the other (Hartley et al, 2010; London, 2003). There should be consistency between the values espoused by the institution and the way it practices these values internally and in engagement with the public. There should also be consistency between the values inherent in the graduate attributes students are expected to acquire and the attributes of the administrators and academics who implement the formal and enact the informal curriculum. The significance of the role of the formal curriculum and the importance of knowledge in cultivating human capabilities for the public good is discussed by Walker (chapter six). As she demonstrates, higher education can make an important contribution to the public good via the graduates it produces. Van Schalkwyk, Herman and Müller (chapter seven) discuss the international literature on graduate attributes in relation to the cold reality of one institutional setting, and suggest that it might be more of a challenge to embed graduate attributes in the curriculum than is expected. This implies the need for overarching change strategies, so that mere intention does not dissipate the potential of higher education to contribute to the public good. Waghid (chapter eight) focuses the discussion on graduate attributes on teacher education in South Africa and, with reference to the work of Martha Nussbaum, on what the politics of humanity and an avoidance of 'shame' might mean in this context.

In order to inculcate graduate attributes for the public good, one requires a curriculum that 'teaches democracy in a democratic fashion' (London, 2003: 25-6). One cannot simply teach about the public good, or for the public good, if one does not provide the opportunity for students to practice these values and attributes and observe them being modelled by others. For this reason, teaching has a special role in developing higher education for the public good (Badat, 2010). There are a number of different ways one can teach for the public good. These include: the use of participatory learning and action (PLA) and encouragement of dialogue (Nicholls and Rohleder, chapter nine); disrupting and resisting stereotypes (Subreenduth, chapter ten); providing 
opportunities for engagement with organisations (Boni, MacDonald and Peris, chapter eleven) and teaching reconciliation whilst encouraging an open approach that allows for contradiction and complexity (Koopman, chapter twelve).

It is also clear from this volume that teaching for the public good is possible in disciplines as varied as theology, education and engineering. Despite the strong influence on many of the authors in this book of Martha Nussbaum's ideas, which stress the contribution of the humanities, it is noteworthy that citizenship and pro-public-good graduate attributes can be fostered in a variety of disciplines, including those outside the arts and social sciences. Boni et al's study on teaching ethics for engineering students has been included to make this important point. All too often in South Africa one hears academics from engineering, mathematics or natural sciences saying that it is all very well to teach for the public good in the arts and humanities, but this cannot be done in our fields.' The study makes an additional important point neglected in the literature: it is possible to use a systematic and rigorous research methodology to show influence of 'pro-public good teaching' on students' attitudes, without having to rely on students' self-reporting.

Many of the contributions in sections three and four are based on research conducted in the teaching of the disciplines, demonstrating that the scholarship of teaching and learning (SOTL) has an important role to play in enhancing teaching for the public good. Contributions from Nicholls and Rohleder, Costandius and Gierdien illustrate the benefits of research on teaching and learning: it encourages a greater systematic understanding and foregrounds student voice, introspection, engagement with the theoretical literature and a deep engagement of theory and practice. It also allows for collaboration amongst academics across boundaries of institution (Nicholls and Rohleder) and disciplinary differences (Boni, MacDonald and Peris). This collaboration permits richer understandings to emerge than would be the case within solitary or parochial settings.

While so much thought is given to the attributes graduates should develop, so little attention is paid to the attributes of the academics who should teach this way themselves (Leibowitz, 2011). Leibowitz and Holgate discuss the kind of attributes that comprise 'critical professionalism', including accountability and agency. The notion of critical professionalism served as the basis of a similarly named project at Stellenbosch University, which became the impetus to this volume. The Stellenbosch project, with its emphasis on interdisciplinary conversations and reflection, is described by Leibowitz and Holgate 
(chapter thirteen). Writers which were linked to the project, by Gierdien and Costandius, stress the value of using research on teaching to foster reflexivity and professional growth. Wisker (chapter sixteen) brings the issues raised mainly in South African teaching and learning contexts back to a broader terrain. Using her experience as an academic developer, she talks about current trends regarding performativity. She maintains that the ideas and strategies inherent in critical professionalism projects are applicable in a wider set of contexts besides South Africa and the United Kingdom - notably Iraq. In doing so she contributes to an idea informing this book: that while it is necessary to hear the voice of the South, that voice should enter into dialogue with perspectives from the North.

There is another aspect of 'dialogue' that informs this book - namely, that there should be dialogue between the various levels of higher education: the macro, meso and micro. Similarly, there should be ongoing debate and reflection amongst the philosophers, sociologists and education experts; and between the administrators, planners, researchers and teachers. Without ongoing and robust interchanges between higher education professionals across disciplines, levels and spheres of influence, it is not possible to achieve holistic and systematic approaches towards higher education for the public good. With this interchange across boundaries of necessity comes a multiplicity of genres, styles and approaches towards enquiry. If one celebrates diversity of identities, can one not celebrate a diversity of discourses?

\section{Note on references to race}

In this book we accept that 'race' is a construction, but that it has material effects. We use the terms adopted in South African government policies, namely, white, African, coloured and Indian. When African, coloured and Indian are referred to collectively, we use the term 'black'.

\section{References}

Altbach, P, Reisberg, L and Rumbley, L (2009) Trends in Global Higher Education: tracking an academic revolution. A report prepared for the Unesco World Conference on Higher Education. Paris: Unesco http://unesdoc.unesco.org/images/0018/001831/183168e.pdf (January 2012)

Badat, S (2010) Towards the theorized development of the teaching and learning capabilities of the next generation of academics. Carnegie Corporation of New York Conference: Developing and Retaining the Next Generation of African Academics: Excellence, Retention, and Sustainability. Nairobi

Badat, S (2009) Theorising institutional change: post 1994 South African higher education. Studies in Higher Education 34(4) 455-67

Bitzer, E (ed) (2009) Higher Education in South Africa: a scholarly look behind the scenes. Stellenbosch: SunMedia 
HIGHER EDUCATION FOR THE PUBLIC GOOD: VIEWS FROM THE SOUTH

Bitzer, E and Botha, N (eds) (2011) Curriculum Inquiry in South African Higher Education: scholarly affirmations and challenges. Stellenbosch: SunMedia

Bosch, A, Rossouw, J, Classens, T and du Plessis, B (2010) A second look at measuring inequality in South Africa: a modified Gini-coefficient. School of Development Studies Working Paper no 58 http://sds.ukzn.ac.za/files/WP\%2058\%20web.pdf(January 2012)

Botman, R (2012) Taking Africa beyond the MDGs: the role of higher education in development. In R Wilkinson and D Hulme (eds) The Millennium Development Goals and Beyond: global development after 2015. London: Routledge

Botman, R (2011) Africa and the MDGs. Global Poverty Summit, Johannesburg. http://www.sun. ac.za/university/Management/rektor/docs/GlobalPovertySummit.pdf (January 2012)

Bray, R, Gooskens, I, Kahn, L, Moses, S and Seekings, J (2010) Growing up in the New South Africa; childhood and adolescence in post-apartheid Cape Town. Cape Town: HSRC Press

Chidester, D, Dexter, P and James, W (2003) whatholdustogether: social cohesion in South Africa. Cape Town: HSRC Press

Council on Higher Education (2008) Academic Freedom, Institutional Autonomy and Public Accountability in South African Higher Education. Report of the Independent Task Team on Higher Education, Institutional Autonomy and Academic Freedom (HEIAAF) no 5 August 2008

Cornell, R (2007) Southern Theory: the global dynamics of knowledge in social science. Sydney: Allen Unwin

Cross, M and Johnson, B (2006) Establishing a space of dialogue and possibilities: student experience and meaning at the University of the Witwatersrand. South African Journal of Higher Education 22(2) 264-83

De Souza, $L$ (2007) Entering a culture quietly: writing and cultural survival in indigenous education in Brazil. In S Makoni and A Pennycook (eds) Disinventing and Reconstituting Languages. Clevedon: Multilingual Matters

Erasmus, D (2006) Living the future now: 'race' and challenges of transformation in higher education. South African Journal of Higher Education 20(3) 51-63

Habermas, J (1971) Towards a Rational Society. London: Heinemann

Hartley, M, Saltmarsh, J and Clayton, P (2010) Is the civic engagement movement changing higher education? British Journal of Educational Studies, 58(4) 391-406

Hemson, C and Singh, P (2010) Shadows of transformation: Inclusion and exclusion of academic staff at a university of technology 24(5) 935-52

Jansen, J (2009) Knowledge in the Blood; confronting race and the apartheid past. Cape Town: UCT Press

Leibowitz, B (2011) Academic literacy as a graduate attribute: implications for thinking about 'curriculum'. In E Bitzer and N Botha (eds) Curriculum Inquiry in South African Higher Education: scholarly affirmations and challenges. Stellenbosch: Sun Media

London, S (2003) Higher Education for the Public Good: a report from the national leadership dialogues. Anne Arbour: National Forum on Higher Education for the Public Good http://www. scottlondon.com/reports/national_forum.pdf (January 2012)

McNiff, J (2011) It takes a township. South African Journal of Higher Education 25(7) 1253-73

Ministerial Committee (2008) The Report of the Ministerial Committee on Transformation and Social Cohesion and the Elimination of Discrimination in Public Higher Education Institutions. Pretoria: Department of Education

Morrow, W (2007) Bounds of Democracy: learning to teach in South Africa. Cape Town: HSRC Press 
INTRODUCTION: REFLECTIONS ON HIGHER EDUCATION AND THE PUBLIC GOOD

National Advisory Council on Innovation (NACl) (2006) South African National System of Innovation; structures, policies and performance http://www.naci.org.za/OECD/OECD\%20Report\%2021 Aug.pdf(March 2009)

Ondari-Okemwa, E (2011) Knowledge production and distribution by institutions of higher education in sub-Saharan Africa: opportunities and challenges. South African Journal of Higher Education 25(7) 1447-69

Parra-Sandoval, M, de Carmona, A, Gonzalez, A (2010) University: the last call? Maracaibo: Ediciones Astro Data

Pattman, R (2010) Investigating 'race' and social cohesion at the University of KwaZulu-Natal. South African Journal of Higher Education 24 (6) 953-71

Scott, I (2009) First-year experience as terrain of failure or platform for development? Critical choices for higher education. In B Leibowitz, S van Schalkwyk, and A van der Merwe, (eds) Focus on First-Year Success: perspectives emerging from South Africa and beyond. Stellenbosch: Sun Media Press

Taskforce on Higher Education and Society (2000) Higher Education in Developing Countries: peril and promise. Washington: World Bank http://www.tfhe.net/report/downloads/report/whole.pdf (December 2011)

Vandeyar, S (2010) Shifting selves: constructing and negotiating academic identities. South African Journal of Higher Education 24(6) 914-34

Von Holdt, K (2012) in M Burawoy and K Von Holdt Conversations with Bourdieu: the Johannesburg moment. Johannesburg: Wits University Press

Walker, M (2006) Higher Education Pedagogies. Maidenhead: McGraw Hill and Open University Press

Walker, M (2001) Mapping our higher education project. In M Walker (ed) Reconstructing Professionalism in University Teaching: teachers and learners in action. Buckingham: SRHE and Open University Press

\section{Acknowledgements}

David Holgate and Susan van Schalkwyk provided valuable commentary which helped in the redrafting of this introduction. 